\title{
O LUTO NO BRASIL NO FINAL DO SÉCULO XX
}

\author{
Mauro Guilherme Pinheiro Koury*
}

\begin{abstract}
Este artigo tem por objetivo contribuir para a compreensão das mudanças comportamentais da população brasileira urbana frente ao fenômeno do luto e da perda. É resultado de um grande mapeamento do comportamento do homem brasileiro, de segmentos médios urbanos, e das mudanças experienciadas na sua sensibilidade, no decorrer da segunda metade da última década do século XX, tendo o processo de luto e da perda como mote analítico.

Palavras-chave: Trabalho de luto. Sentimento de perda. Sofrimento. Vergonha. Individualismo. Brasil urbano.
\end{abstract}

INTRODUÇÃO

Encontra-se em pleno desenvolvimento, no Brasil dos últimos cinquenta anos, um processo de individualização das relações sociais e nas formas de agir e pensar individuais. Viver essa experiência parece estar provocando nos brasileiros - de segmentos médios urbanos, principalmente - um sentimento de desorganização e um aumento da tensão pessoal e grupal.

Define-se como segmentos médios urbanos, neste artigo, uma população com renda entre 06 e 20 salários mínimos, e com educação formal entre o nível médio completo e o superior. Foi essa população que se apresentou à pesquisa, com um total de $62,87 \%$ dos indivíduos que responderam e devolveram os questionários considerados válidos, bem como se predispuseram a constituir a amostra posterior para o aprofundamento em entrevistas

* Doutor em Sociologia. Professor do Programa de PósGraduação em Antropologia da Universidade Federal da Paraíba.

Cidade Universitária. Cep: 58051-900. João Pessoa - Paraíba - Brasil. Caixa-postal: 5144. maurokoury@gmail.com abertas. ${ }^{1}$

Em sua maior parte, os informantes desta pesquisa se constituíram de profissionais liberais, comerciantes, empresários e militares, sem esquecer, contudo, uma grande participação de aposentados, donas de casa e estudantes. O número maior de respostas, que retratam o nível de renda, de escolaridade e o perfil das profissões dos informantes, assim, vieram de entrevistados situados no que se convencionou aqui chamar de segmentos médios urbanos.

A configuração de um problema sobre a não similitude da distribuição dos entrevistados segundo as faixas de renda e a escolaridade a partir dos padrões existentes na sociedade brasileira, contudo, revelou-se para este trabalho um elemento importante de análise. A motivação dos segmentos médios urbanos em responder a esse tipo de questionário tornou-se um dado interessante por, aparentemente, ser

${ }^{1}$ Durante os anos de 1997 a 1999, foram realizadas, em todas as vinte e sete capitais de estados brasileiros, para a pesquisa Luto e Sociedade, então em desenvolvimento no GREM, Grupo de Pesquisa em Antropologia e Sociologia das Emoções, da Universidade Federal da Paraíba, aplicações de questionários com 1304 informantes, e 259 entrevistas abertas, com uma segunda amostra a partir dos 1304 respondentes, com o sentido de aprofundar as reflexões iniciadas nos questionários. 
nesse segmento que se configuram uma maior sensibilidade ao novo e uma ambiguidade em relação aos padrões de tradição em que potencialmente estão inseridos como habitantes de cidades específicas.

Velho (1986, p. 86 e 89), trabalhando com segmentos de classe média da cidade do Rio de Janeiro, revelou os desencontros dos indivíduos que a informam diante do domínio público e uma tendência à centralização em torno de um conjunto de valores em que a sociabilidade de caráter mais intimista é o valor-chave de compreensão. A tensão entre os espaços público e privado parecem nortear, assim, a avaliação do ser sujeito no mundo, através de uma fragmentação acelerada das esferas de vida social e cultural em que ele está inserido.

Os segmentos médios urbanos, dessa forma, ao se disporem prontamente para as respostas solicitadas em um questionário sobre a relação entre luto e sociedade, mais do que as outras de status social mais baixo e mais alto, parecem manifestar sua inquietação com os processos por que passa a sociedade nacional nesses últimos cinquenta anos. São processos que os atingem, criam tensões e os colocam em choque com as regras de etiqueta que parecem não mais satisfazer as práticas cotidianas, mas que ainda se encontram consolidadas no maginário social e na expectativa de cada um ฮิ atitudes morais.

\& volvendo para uma situação melhor O sentiลิ mento afigura-se em ser de desconforto e in-

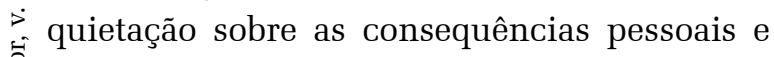
grupais de tal caminho.

Weber (1944), na primeira parte do seu livro Economia e Sociedade, faz um esforço para caracterizar, no processo de racionalização social vivido pela sociedade europeia no momento de consolidação do capitalismo, a diferenciação estabelecida entre ação social e ação não social, esta última conduzida especificamente por construções subjetivas no interior de sujeitos individuais específicos, descaracterizando-a assim da objetividade social das ações.
Já não se aceitam mais as antigas regras relacionais da cultura brasileira vividas até meados da década de sessenta do século XX. Elas vêm se tornando incômodas e, para muitos, olhadas até com desprezo, como incultas ou incivilizadas, mas, também, não há um sentimento de adequação aos rumos individualistas que tendencialmente vêm tomando conta das relações sociais e individuais na sociedade contemporânea.

Certa apreensão, não de todo consciente com a incerteza do mundo atual, parece provocar, em outros tantos, uma tentativa de segurar as relações tradicionais com as quais estavam acostumados a viver, mas, ao mesmo tempo, essa tentativa vem acompanhada de um sentimento de que as regras passadas já não mais se adéquam às questões do presente. $\mathrm{O}$ que faz aumentar e ampliar a insegurança e a falta de sentido pessoal.

A ambiguidade nas relações e nos sentimentos expressos parece ser, assim, o eixo central por onde devem ser pensadas as relações de sociabilidade no Brasil do século XXI. A experiência vivida como um conjunto societário, porém, nunca é igual para todos os seus membros, e os rumos dessa mudança é sempre assimétrica e desigual. Essa consciência analítica afigura-se como fundamental para que se possa compreender a experiência de ambivalência individual e grupal de uma sociedade em processo acelerado de mudança, como a brasileira.

O objetivo central da pesquisa mais ampla na qual este artigo se baseia buscou compreender as atitudes em relação ao fenômeno do luto no Brasil nos anos finais do século XX. Duas inquietações importantes nortearam a análise: a primeira se refere ao entendimento de como foi internalizado, como processo simbólico, o significado social do sofrimento no imaginário brasileiro; e a segunda, por quais mudanças tem passado o fenômeno do sofrimento causado pelo luto, e que reações a esse fenômeno tem enfrentado junto aos indivíduos pertencentes às camadas médias urbanas. 
Interessa a este artigo, assim, verificar o lado público do sofrimento de quem fica no momento seguinte imediato à constatação da morte. Compreender as expressões de dor, de desespero, de desamparo, ao lado de reuniões sociais onde parentes e amigos presentes bebem, comem e conversam o morto. O entendimento desse ritual solitário do sofrimento e do ritual social da despedida, se entrecruzando em gestos, expressões e atitudes, em constantes movimentos de mudança e permanência, fornece a base de inquietações deste trabalho.

A hipótese inicial de trabalho foi construída a partir da ideia de que quanto menor o centro urbano mais tradicional seriam os costumes e as expressões locais de sentimentos, por seus membros se encontrarem envolvidos em relações comunitárias intensas e presos, ainda, a fortes tradições familiares, religiosas ou de cunho moral. Quanto maior o centro urbano, ao contrário, as relações individualistas seriam ressaltadas pela população e mais dinâmicas seriam as mudanças nos hábitos locais das comunidades e indivíduos estudados, ligados ao trabalho de luto e às representações sobre a morte e o morrer.

Essa hipótese inicial foi sendo modificada no decorrer da análise. O dinamismo das relações sociais associadas aos grandes núcleos urbanos tem por trás um modelo de cidade erguido nos finais do século XIX e que se consolidou durante todo o século XX. Nesse modelo, o espetáculo do anonimato pelo e através do grande conglomerado populacional quebrava barreiras da tradição pela destruição de práticas rituais comunitárias, libertando os indivíduos das amarras sociais e os fazendo encarar ou enfrentar a sociedade como um desafio a ser vencido por e através de suas próprias forças e representações.

A ideia de metrópole como um espaço onde as tradições seriam constantemente desfeitas e remontadas em novidades crescentes, e onde existia uma tendência a uma presentificação das relações sociais que, por sua vez, se encontravam sujeitas a uma lógica de mercado e de individualidade extremadas, permeou a representação das cidades modernas em muitos autores que buscaram estudar e compreender a modernidade. De Simmel e Tönnies a Weber, passando por Durkheim, Marx e a Escola de Frankfurt, nos escritos de Benjamin e Adorno, foram aferidas nuanças sobre esse modelo de cidade onde a dissolvência do homem público cedia lugar cada vez mais a um indivíduo interiorizado e preso a um espaço privado de si mesmo.

A polaridade entre a ideia de comunidade e de sociedade ficaria, assim, como um pano de fundo comum à ideia de que pequenos grupos societários, a comunidade, seriam um lócus de tradição, ao passo que os grandes grupos societários, a sociedade, encarnada aqui através da forma de metrópole, seriam o local ideal para o desenvolvimento do individualismo e do indivíduo interiorizado e privado. Teve-se o cuidado, neste trabalho, porém, de não considerar as referências a maior e a menor, presentes na hipótese inicial, como dois polos antagônicos, mas de observá-las em relação, como frutos desiguais de processos de modernização por que passou e vem passando a sociedade brasileira a partir dos anos de 1970 aos dias atuais.

Grande foi a surpresa ao verificar, através dos dados levantados, que não existe um processo de equivalência entre maior centro urbano e menor número de respostas favoráveis a práticas ritualísticas ligadas ao luto e aos processos da morte e do morrer ou presas à tradição, ou vice-versa. As respostas enviadas pelos diversos centros urbanos brasileiros, capitais dos vinte e sete estados que compõem a nação, são muito próximas nas suas indagações, inquietações ou indignações a respeito dos costumes e hábitos ligados à prática do luto e da morte no Brasil, o que encaminhou o trabalho para o abandono da hipótese inicial e para um novo tipo de indagação sobre o processo em que se debate a população urbana brasileira em seu conjunto, em relação ao uso de hábitos e costumes e suas representações 
ligadas ao ritual da dor e da morte.

Esse novo conjunto de indagações deixou de lado as relações entre os conceitos de tradicional e moderno e buscou ressaltar as conformações e os modos de vida nacional como expectativas de uma população urbana sujeita aos mesmos estímulos e práticas de ação, e as adequações locais e regionais experimentadas e assumidas por cada capital em função de sua formação específica como cidade e como origem.

Após os anos de 1970 e, principalmente, após os anos de 1980, o Brasil passa por uma série de transformações estruturais e culturais que tornam comuns as expectativas e o conjunto de experiências reais e imaginárias sobre regras de comportamento e ação a todo o complexo urbano da nação. A posição frente à vida e os hábitos e costumes da população permitem pensar em um padrão nacional, embora com coloridos e especificidades comuns a cada região e a cada cidade específica.

As conformações urbanas, assim, respondem aos mesmos estímulos e frequentam o mesmo imaginário, remetendo-o, por sua vez, para as cores e padrões específicos locais. Local e nacional, desse modo, vivem uma constante inter-relação e um estado de reformulação contínua que, se, de um lado, enfraquece as bases da tradição como elemento sentimental de resguardar práticas específicas locais, por outro lado, refere-se cada vez mais a práticas específicas locais para pensar o nacional e o mundo.

A modernidade, desse modo, parece configurar práticas e pensamentos cada vez mais intricados em uma rede nacional de referência comum, porém pensados e agendados $\therefore$ a partir de cada tecido organizacional local, ลิ seja como choque ou conflito inevitável com o costume e a moral sedimentados, seja ainda como conformação de novos hábitos e práticas impessoais da sociabilidade emergente nos últimos trinta anos no país. Um e outro servem como contraponto às formas de compreensão possíveis das configurações atuais do homem urbano brasileiro.
Este artigo, contudo, se prenderá mais do que nas possibilidades de adaptação dos sentimentos e indagações comuns a cada local, nas próprias expectativas e experiências reais e imaginárias do homem urbano brasileiro contemporâneo, tomado como um todo. Não se deterá no colorido local de cada cidade, a não ser quando necessário para exemplificar alguma atitude ou reação particular e específica.

O campo de análise investigado estará delimitado, assim, às estruturas comuns informadas pelas respostas dos entrevistados às questões formuladas. Anotam-se, aqui, mais as semelhanças das inquietações que norteiam o desvendar do homem urbano nas cidades brasileiras de hoje, do que as formas de apreensão desse sentimento comum e as adaptações possíveis por região, estado ou cidade específica.

\section{A DISCRIÇÃO}

Neste artigo, procurar-se-á identificar como os brasileiros urbanos, de segmentos médios, estão vendo essas mudanças e inquietações sobre o prisma do comportamento de uma pessoa que sofreu uma perda, ou em relação a outras que a experimentaram. Nele se discutirá o processo de ação social e a construção de significados e tentativas de nomeação, reais, imaginárias e relacionais, sobre a perda, o luto e o sofrimento, a partir dos depoimentos de informantes, como entrevistados ou que se dignaram a responder o questionário-padrão desta pesquisa.

Um dos pontos de partida será o de analisar como pensam os informantes que responderam ao questionário-padrão e às entrevistas abertas desta pesquisa sobre o comportamento de uma pessoa que sofreu uma perda. As respostas à questão podem ser divididas em três categorias analíticas. A primeira, "Ser discreto", obteve $77,60 \%$ das respostas; a segunda, "Seguir a tradição”, 15,34\%, e a terceira, por fim, "Não existe comportamento ideal", 7,06\%.

A discrição, assim, parece movimentar 
a ação imaginária dos informantes sobre o papel comportamental de um sujeito que sofreu uma perda. Como já se vem analisando ao longo deste trabalho, desde o final do século XIX vem ocorrendo uma diminuição da demonstração ativa de sentimentos no momento do trespasse do morto, ou do sofrimento causado nos entes queridos vivos.

O morrer e a morte vêm sendo retirados progressivamente do ritual público que os circundava, o que é movido, em parte, pela emergência de um novo discurso de poder, o poder médico, junto a ações de políticas públicas sanitárias e higiênicas para as cidades, e também pela emergência da insalubridade causada pelas doenças e pela morte, no imaginário popular. As representações sociais sobre a morte e o morrer parecem ter tido sua mudança acionada, assim, principalmente, através do medo causado pelas inúmeras epidemias que tomaram de assalto as cidades brasileiras nas últimas décadas do século XIX, e pelo discurso de autoridades sanitárias de controle da saúde pública e pessoal.

Os enterros, os cortejos e os velórios tornaram-se progressivamente mais rápidos, com o morto e a morte identificados como poluidores e, pior, transmissores de doenças, embora, ainda na metade do século XX, expressões de dor e demonstrações objetivas de luto fizessem parte do cotidiano da população brasileira. O vestir preto, o resguardo dos enlutados, a abstinência de alguns alimentos e de uma vida social ativa, ainda eram esperados dos familiares do morto. Era esperado, também, o acompanhamento mais de perto de parentes e amigos, e de outras instituições sociais, que funcionavam como instâncias pessoalizadas, tais como a Igreja - através de um discurso sobre a outra vida e o conforto aos que ficam -, ou sociedades secretas, tipo a Maçonaria, por exemplo, que amparavam as viúvas e filhas solteiras e menores, nos primeiros meses após o trespasse, ou se solidarizavam com seus membros masculinos pela perda de um ente querido, apoiando-os em seu sofrimento. Mecanismos de reintegração ao trabalho e à vida social ativa também eram estimulados de forma pública a quem perdesse alguém caro em termos de proximidade e afeto.

As demonstrações públicas do sofrimento, dessa maneira, embora em declínio e menos acentuadas do que no final do século XIX, permaneceram por várias décadas do século $\mathrm{XX}$, até aproximadamente o decorrer dos anos de 1960, entre os habitantes urbanos brasileiros. Largas parcelas da população pareciam ainda se guiar na tradição de guardar, velar e sofrer pelos seus mortos sob uma regência pública, bem como até a dialogar com eles, como lembra DaMatta (1987). O apoio da sociedade para a superação do sofrimento e reintegração social era, também, esperado.

Com a modernização brasileira dos anos setenta e, principalmente, com o esvaziamento progressivo do campo no Brasil, tem início uma transformação mais intensa no comportamento e hábitos da população brasileira, especificamente de segmentos médios urbanos. Antigos hábitos são rapidamente deixados para trás por não serem considerados urbanos, principalmente no que diz respeito às relações familiares.

A família extensa tendeu progressivamente a diminuir de tamanho e a ser considerada apenas como e através do núcleo familiar básico, composto do pai, da mãe e dos filhos. Nos anos setenta, também, teve início o processo - que já vinha ocorrendo na Europa e nos Estados Unidos -, da saída mais cedo dos filhos e filhas adultos jovens de casa, para uma vida mais independente da casa paterna, principalmente entre os de classe média. ${ }^{3}$

${ }^{3}$ É importante salientar, porém, que uma tendência à permanência maior dos filhos, chegando às vezes até os trinta anos de idade, na residência dos pais, parece ter acontecido entre os jovens de classe média no Brasil, nos anos noventa do século XX, e que parece prosseguir agora, na primeira década do século XXI. Esse fato, contudo, não parece ter vindo acompanhado de uma restauração de um parece ter vindo acompanhado de uma restauraçáo de um
hábito do passado, rompido pelos jovens dos anos setenta; pelo contrário, essa nova forma de organização familiar parece ganhar espaço entre os jovens como uma forma de ampliação do espaço de individualidade e segurança para o enfrentamento do mundo, talvez pelo aumento do tempo de especialização e formação profissional, talvez pelo apelo aos prazeres da vida e à formação de uma poupança pessoal, talvez, enfim, pelo conforto e descompromisso de 
O ritmo de vida, por outro lado, tornouse gradativamente mais acelerado, afastando os indivíduos uns dos outros e os tornando mais reservados perante as próprias emoções e incomodados com a expressão pública de sentimentos de outros. Outro fator bastante interessante é o desenvolvimento da psicanálise no Brasil, também ocorrida nos anos setenta, junto a segmentos médios urbanos intelectualizados

A autoanálise e o divã do psicanalista progressivamente atraem a atenção dos membros urbanos de classe média, principalmente adultos jovens, numa faixa que vai dos 18 aos 35 anos. Essa tendência associa-se ao desapego aos valores tradicionais de comportamento vividos e questionados por esses jovens, e a falência progressiva, nos anos oitenta, de paradigmas norteadores de uma esperança em um mundo melhor no futuro, ou em instâncias pessoalizadas, como a própria família tradicional, a religião, o partido político e outras mais.

Não se pode esquecer também da importância crescente de uma competitividade no mercado de trabalho, o que amplia a margem da disputa e dispersão de uma parcela jovem da população urbana recente brasileira.

Os anos setenta e oitenta do século XX, desse modo, estabelecem o grande marco da transformação por que passaram e ainda passam os habitantes urbanos no Brasil. Independentemente do tamanho populacional das cidades, aqui se tratando especificamente das capitais de estados brasileiros, esses marcos servem como norteadores da identificação e modificação ocorrida no comportamento do brasileiro urbano de classe média, em especial. Isto porque, progressivamente também, a par$\dot{A}$ tir dos anos sessenta, e principalmente setenta Aิ dos novecentos, ampliou-se a margem de concentração política, econômica e comunicacional do país.

afazeres domésticos do cotidiano que a casa dos pais possibilita. Em todos os casos, porém, não parece refletir em uma volta ou em um maior apego a tradições culturais perdidas, mas em um aumento do individualismo como espaço de consumo e lazer, e como espaço de competitividade no ambiente societário formal das relações, econômicas políticas, ou ligadas às esferas sociais da hierarquização e do status.
Os estados brasileiros, as cidades e, especificamente, as capitais de estado, através de seus habitantes de classe média, viveram uma exposição maior dessa concentração. Os hábitos comportamentais, os desejos e buscas de realização ficaram cada vez mais concentrados em um único eixo, o Rio de Janeiro e São Paulo, o que aumentou, assim, um aparentemente único desempenho comportamental, embora segmentado internamente, entre os indivíduos de classe média, em todo o Brasil.

Uma estratificação no interior dessa centralização se faz visível, com fortes componentes de uma ampliação do preconceito sobre estratos, de acordo com a inserção do cidadão em um núcleo urbano mais perto ou mais longe, mais rico ou mais pobre, do Brasil, assim como, internamente a cada capital, de acordo com as formas de vida que levem os grupos e segmentos diferenciados de sua população.

Isso parece fazer aumentar ainda mais o sentimento de solidão do homem urbano de classe média brasileira. O "ser discreto" parece representar, assim, a forma que vem assumindo a "economia de afetos" (Elias, 1990, p. 49) da cultura urbana brasileira dos últimos trinta anos, principalmente aqui, no tratamento da questão da cultura funerária.

As convenções de estilo, as formas de intercâmbio social e o controle social das emoções parecem viver, no Brasil urbano, principalmente junto aos segmentos médios urbanos, uma transformação intensa. Tal transformação se evidencia numa maior economia dos gestos, da postura, do decoro corporal externo, nas formas do olhar das pessoas, da expressão facial, entre outras atitudes comportamentais.

Essa mudança caminha aceleradamente para a composição de um estilo de vida e de uma forma de expressão da autoimagem individual através de uma ação de autodistanciamento, onde a vergonha e o sentir-se embaraçado constituem-se em uma viga mestra para um maior controle emocional - seja pela repressão das atitudes espontâneas de sentimento e pela internalização na pessoa da subjeti- 
vidade, como uma ação não social, ${ }^{4}$ seja pela autodisciplina.

O "ser discreto", desse modo, caracteriza o modus operandi por onde se pode compreender a construção social do indivíduo urbano brasileiro de classe média, hoje. O comportamento pessoal de discrição perante as expressões das próprias emoções é sentido também nas informações contidas no questionário aqui analisado, na relação desse sujeito individual com os outros. Em outra questão levantada no questionário, perguntou-se qual deveria ser o comportamento dos outros, isto é, da sociedade, em relação às pessoas que sofreram uma perda.

Três categorias foram elaboradas a partir das respostas obtidas dos informantes. A primeira categoria afirma que o comportamento deveria ser o de "dar apoio", com 18,71\% das respostas. A segunda categoria alega que a atitude das pessoas em relação à outra que sofre uma perda, deveria ser a de "não importunar", com $72,01 \%$ do total, a terceira categoria, por sua vez, com 9,28\% das respostas, diz que a forma de comportar-se, em uma situação como esta, "depende do caso".

As respostas a essa questão são significativas para a análise aqui realizada, por dois motivos principais. O primeiro, por estabelecer, com o "não importunar", uma esfera de pudor de chegar-se ao outro, como se uma expressão de solidariedade ou apoio pudesse ser compreendida pelo indivíduo objeto da ação como uma espécie de invasão de privacidade. Constrangido em sua dor e em seu sofrimento pessoal pela perda recente, o indivíduo poderia, segundo essa categoria, sentir-se ofendido pela tentativa de aproximação do outro, retirando-o e comprometendo o seu espaço individual no social.

O segundo motivo diz respeito à ideia de contaminação social pelo sofrimento do outro. $\mathrm{O}$ medo do envolvimento emocional através da demonstração de atitudes de solidariedade e apoio ao outro configura o ator em personagem tímido e, consequentemente, retraído nas ${ }^{4}$ Ver a nota 2 . suas demonstrações de afeto, como se elas pudessem comprometê-lo, ou pôr em risco o seu desempenho social.

Nesses dois motivos expressos, assim, parece posta em evidência uma tendência ao sentimento de envergonhar-se frente às dificuldades de chegar ao outro, seja através do agir com discrição, presente na categoria do "ser discreto", como um dever ser moral para todos aqueles atingidos por uma perda, seja pela busca de não intromissão, cristalizada na categoria analítica de "não importunar" aqueles em sofrimento.

Nas duas formas do como se comportar frente à perda, pessoal ou de outros, fica evidente o medo de não saber como enfrentar a situação, e a culpa por ele provocada, o que parece aumentar o sentimento de isolamento e desamparo vivido pelo indivíduo urbano de segmentos médios brasileiros na contemporaneidade.

\section{ECONOMIA DE EXPRESSÕES DE AFETOS}

Goffman (1967, p. 9), analisando as expressões faciais, descreve a expressão "perder a face" (to lose face) como o receio de não saber como se referir ou representar em uma situação determinada. Ele fala do medo do indivíduo de poder possibilitar uma impressão errada nos outros, ou de poder vir a ser avaliado com um desempenho fraco, ou péssimo, na demonstração de sua incredulidade ou de sua capacidade de suportar a realidade que se apresenta. Ou mesmo de sentir-se envergonhado e indisposto na situação vivida em um momento relacional específico.

Esse receio de perder a face, trabalhado por Goffman (1967, p. 9), parece agir nos indivíduos em relação através de uma economia gestual das emoções. Economia de gestos que possa garantir aos sujeitos a "capacidade de suprimir e ocultar qualquer tendência a ficar envergonhado durante os encontros com os outros". E, dessa forma, impossibilitar qual- 
quer forma de avaliação, a não ser a que objetivamente quer expressar.

Essa economia de expressões de afetos, assim, parece se realizar através de uma postura de distanciamento ou de afastamento da situação experienciada na relação com o outro. Trata-se de uma atitude de leve indiferença aos outros sociais, seja quando o indivíduo sentese evocado como objeto da ação, onde a exigência de um autocontrole pela discrição é a certeza de não apresentar-se constrangido por constranger o próximo; seja também quando o indivíduo seja ou apareça como o sujeito da ação, onde o não incomodar alivia a dificuldade de expressão de sentimentos.

Rezam as regras de etiqueta no Brasil urbano contemporâneo, que, em uma situação de sofrimento, na qual um indivíduo não pode ausentar-se de todo, mas que também não quer invadir a privacidade de quem a experimenta, ele deve enviar um cartão, flores, ou algo semelhante. Através deles, deve expressar condolências ou solidariedade ao outro, e, mesmo assim, após alguns dias do fato ocorrido, ou quando houver uma cerimônia, como a missa de sétimo dia, por exemplo, fazer-se presente e, se próximo, cumprimentar o outro, na fila de condolências, com uma expressão contida, e ir embora, deixando ao outro a possibilidade de introjetar sua dor privadamente. i perda. Cabe-lhe manter a dignidade e o controle de suas emoções, aceitando as condolências com um ar contido, e com uma ligeira indiferença no olhar.

Ambos parecem refletir a atitude blasé, diagnosticada por Simmel (1967) no início do a século, para expressar a leve indiferença no j olhar e no gestual do homem citadino na metrópole contemporânea, e o processo de multidão e anonimato em que parece emergir a afirmação da individualidade no momento de consolidação do capitalismo.

Essa busca de ocultação da face ou a leve indiferença presente na atitude blasé tornam-se, cada vez mais, expressões em uso no cotidiano comportamental do homem brasileiro urbano. As expressões comportamentais outrora presenciadas pelos próprios sujeitos, ou relatadas por parentes, ou visualizadas através de experiências presentes ainda no hoje, através da imprensa ou por próprio testemunho, tornam-se aparentemente estranhas ao cotidiano do sujeito, como arcaísmos de uma estrutura mental e emocional diferente.

Trata-se de movimentos narrativos estranhos que parecem incomodar o homem moderno brasileiro, como parte de uma estrutura de um passado que se quer esquecer, ou melhor, distanciar-se, por incivilizado ou não moderno. Há um receio também de que sua presença, pelo excesso emocional presente, contamine a si mesmo e as relações sociais de onde emergiram, paralisando o presente da modernidade vivida pela vergonha de validar, num outro qualquer, uma imagem avaliativa que comprometa pessoal ou em grupo seu desempenho e seu estatuto de urbano.

Autores como Van Gennep (1978), Junqueira, (1985), entre outros, buscaram, em seus trabalhos, demonstrar que as marcações, os ritmos e os ritos são essenciais ao movimento cotidiano de toda sociedade. Que nenhuma forma de sociabilidade flui sem qualquer tipo de passagem, ou, como afirma DaMatta (1983, p. 39), “[...] é a própria passagem que constitui o polo talvez mais básico da própria idéia de mudança”.

Quando a mudança é acelerada, porém, os ritmos que regulam a passagem parecem embaralhados. Se, por um lado, eles são vistos, através de atitudes de estranhamento, como resquícios incômodos de um passado presente, por outro lado, o lidar com as novas formas emergentes não parece ser fácil, o que ocasiona um mal estar crescente em quem se vê obrigado - por ter acontecido consigo, ou por estar envolvido em uma situação específica - ou intimado a participar de cenários onde possíveis elementos de passagem - a morte, o morrer, o sofrimento, o luto, aqui trabalhados - se configuram.

O receio de contaminação, por parte de 
quem sofre uma perda, ou por parte de quem acompanha um processo de luto, por exemplo, faz com que haja um retraimento nas formas de etiqueta, para uma quase ausência de gestos e emoções. Um "ocultar a face" (hide face), nos dizeres de Goffman (1967), por medo de "perder a face" (to lose face), configura-se como uma espécie de escudo protetor de ambos os lados de um processo interativo, o que ocasiona dificuldades e incômodos de lado a lado das relações, por não saber como se comportar, ou não estar preparado para o exercício de um dado e específico papel, pois, possivelmente, as emoções e as validações da face e de gestos serão objetivamente analisadas e avaliadas pelos demais presentes.

O medo de não saber se expressar e se comportar em uma situação específica, como a morte e o luto, por exemplo, funciona como uma regra de convivência que sobrepõe, sobre a mesma ação, elementos de uma estudada indiferença facial frente aos elementos da relação e uma busca interna de saber-se, ou melhor, querer-se encontrado por outro. Indiferença e procura se mesclam em uma atitude que parece incomodar e isolar ainda mais os indivíduos envolvidos em uma relação.

É uma ambiguidade presente em sensações aparentemente contraditórias, pois elas se revelam, de um lado, associadas a uma espécie de desprezo do passado, embora sejam associadas a ele. O passado é visto pejorativamente como cenário de costumes de uma época caipira ou de tradição rural, ou do Brasil de antigamente. Ao mesmo tempo, por outro lado, sofre-se idealmente de uma forma de saudade do passado, agora visto de forma glamorosa, como algo que se perdeu e que trazia mais solidariedade e conforto.

Isso pode ser visto no depoimento de uma informante ${ }^{5}$ que perdeu a mãe, com quem tinha afinidade e a considerava como sua única confidente e amiga:

${ }^{5} 50$ anos, professora universitária e natural da cidade de Salvador.
Eu fiquei sem saber o que fazer com o choque enorme que senti quando minha mãe morreu. Eu fiz pra mim uma máscara dura, uma fortaleza, para acompanhar todos os preparativos para as exéquias. Desde a liberação do corpo até a marcação do lugar do velório, o próprio velório, a compra de um lugar no cemitério, o enterro, a missa de corpo presente, o retorno para casa, até a missa de sétimo dia, eu parecia não ser eu mesma. Não entendia onde pude achar tanta força para fazer tudo e não desmoronar [...] Chorava e gritava por dentro, mas, por fora, me esforçava para não demonstrar o que se passava dentro de mim. Claro que devia estar com a cara arrasada [...] É até natural nas circunstâncias que vivi naquele momento, mas parecia calma, segura, tranquila e ativa. Comandei toda a situação, para que nada faltasse à minha mãe na hora de sua despedida [...] Atendi a todos com atenção, até a alguns parentes que não eram muito chegados e que apareceram com aquelas costumeiras e horríveis cenas de choro em excesso [...] Confesso que, em alguns momentos, tive que intervir delicadamente, para que eles não nos matassem de vergonha, que se controlassem [...] Pareciam vindo sei lá de onde [...] Constrangendo todos os presentes com aquele excesso, falso, parecia falso, como que querendo aparentar uma emoção que não estavam a sentir. Eu, que sou eu, que perdi minha única amiga e confidente, a minha mãe, estava controlada, por que eles não deveriam também de estar [...] Uma das coisas que fiquei magoada, porém, foi a falta de atenção de algumas pessoas que eu considerava [...] Não que não estivessem presentes em algum momento da despedida de minha mãe, mas por não verem o meu sofrimento intenso, a dor que despedaçava o meu íntimo [...] Queria ser buscada, consolada, que me vissem como eu era [...] Mas não, eram condolências frias, distantes, contidas, como se quisessem se ver livres daquele espetáculo [...] Eu até, passado algum tempo, conversando com uma amiga a respeito dessa solidão grande que eu senti, e ainda sinto, ela me pareceu assombrada com a minha "cobrança" - foi assim que ela definiu o meu sentimento -, pois, segundo ela, eu estava tão forte que até ela se intimidou, por não se achar tão forte como eu e me constranger com a sua pieguice [...] Antigamente não devia ser assim, conforme minha mãe falava e os da época dela falavam; parecia existir uma atenção especial que envolvia as pessoas e as tornava mais solidárias umas com as outras. O entendimento do que se passava no ser de alguém era como que sintonizado por todos os presentes, que o confortavam e o amparavam. Agora é só solidão de todos os lados, ninguém parece, ou quer, 
compreender ninguém [...] Cada um que viva a sua dor sozinho, e pronto! (Entrevista n. 27).

Nesse depoimento se tem, de um lado, uma espécie de asco, quase repugnância a gestos demasiados por parte de presentes, em um processo de despedida de alguém morto. $\mathrm{O}$ excesso parece incomodar e causar vergonha e, inclusive, também, denota um fingimento de sentimentos, na verdade ausentes, em quem pranteia e se expõe em demasia.

O excesso de emoção em público parece vir à tona e ser entendido pelos parceiros da relação como falsidade. Fazem parte de atitudes de possíveis relações sociais de um passado sequer lembrado, a não ser pela falta de decoro e de pudor nele expresso no hoje, e que se quer esquecer e, se possível, negar que existiu, a não ser pela falta de educação inerente a tal gestuário.

De outro lado, esse depoimento revela também o seu contrário: a solidão dos indivíduos prisioneiros do pudor, e a vontade, ou mesmo necessidade de alguém que os veja além da máscara de contenção com que reprimem seus sentimentos. O passado, então, é relembrado como um tempo de solidariedade e compreensão das emoções. É rememorado em uma visão nostálgica de algo que se perdeu irremediavelmente e que condena ao isolamento de cada sujeito dos demais, em seu sofrimento.

Tal ambiguidade parece ser comum à maioria dos indivíduos de classe média entrevistados nesta pesquisa. Ela parece fazer parte, também, desse momento de transição vivido pelo povo brasileiro nesses últimos cinquenta $\checkmark$ anos, tornando difusas as fronteiras que deli\& mitam a marcação e os ritmos sociais de cada ลิ passagem, ao transportá-los para o íntimo dos sujeitos como expressões não sociais.

A objetividade das relações amplia a necessidade de autocontrole e a separação radical entre indivíduo e sociedade. O ritual vem sendo suprimido ou abreviado de tal forma, que apenas deixa aparente, no caso das cerimônias fúnebres, o essencial e higiênico da configu- ração da morte e do despacho do corpo, e um evitar aparente de sentimentos no lidar com o fato. Quando muito, ele se expressa no interior de uma solidariedade formal e constrangida de ambos os lados da relação, entre o que sofreu a perda e os outros.

Tal contexto parece aumentar o sentimento de culpa e o desconforto de não saber como se situar e se apresentar em cada situação específica. Parece, assim, que as relações sociais se tornam relações de constrangimento e pudor. Configuram-se num elaborar constante da face, para que ela não apresente outra coisa além de uma indiferença presente, construída para a ocasião, e que também revele, para alguns poucos, uma ansiedade de ser olhado mais a fundo, no interior de sua face, $\mathrm{e}$ ser encontrado, e apoiado e tomado como realmente se é, o que não acontece e aumenta a solidão e o constrangimento pessoal de todos.

\section{OS SENTIDOS DA PERDA}

O que será perda, ou melhor, como foi definida a noção de perda para os informantes do questionário-padrão? Uma questão sobre o significado do termo "perda" foi elaborada entre as várias outras constantes, pedindo, inclusive, no seu desenvolvimento, uma separação entre perda e sofrimento, entre perda e luto, e entre perda e morte. Para os informantes, a perda poderia ser definida em quatro categorias analíticas: como "ausência", para 32,75\%, como "desaparecimento", em um conjunto de 21,01\% das respostas, como "perda de si", para $38,42 \%$ e, como "dano", para 7,82\% das respostas.

O sentido de "perda de si", elaborado a partir de um conjunto de $38,42 \%$ das respostas à questão, parece possuir o significado amplo de perda de referenciais que permitiam aos sujeitos se localizarem em uma situação social determinada, tornando-os retraídos e inseguros até dos seus próprios papéis no mundo. Aparecem, nessa categoria de apreensão da noção de perda: a ruptura com o passado e o viver o 
futuro como uma presentificação alucinada, a falta de amarras, e até o menosprezo expresso pela reminiscência de formas culturais consideradas arcaicas e não condizentes com um padrão - indefinido, é bom frisar - de urbanidade.

Por ela é possível considerar o alto grau de ruptura vivido pelos segmentos médios urbanos no Brasil nesta entrada do século XXI, com as construções categoriais de uma tradição cultural que parece não mais satisfazê-los. Entretanto, ao mesmo tempo, eles não têm ideia de uma nova forma de apropriação social de si mesmos com a qual pudessem contar em momentos de crise ou perigo, como os vividos por uma passagem brusca ocasionada por um processo de perda qualquer.

$\mathrm{O}$ risco ocasionado por esse processo de perda é a perda de si mesmo, uma definição dramática que isola o indivíduo da sociedade. $\mathrm{O}$ indivíduo é visto como um ser completo e indivisível, fora e em conflito permanente com o social; e a sociedade, por seu turno, é entendida como um conjunto de regras que busca constrangê-lo a uma situação passiva e alheia de sentimentos, ideias e volições.

Parece ser esse o caso expresso nos fragmentos de narrativas que se seguem:

Quando vi o corpo de meu pai no centro de um velório com um bando de pessoas que nem ao menos falavam com ele quando vivo, por ser considerado velho e doente, senti a hipocrisia toda do mundo. Era algo que eu já sentia e não sabia bem o que era [...] Na minha frente, aquelas pessoas me deram bem a dimensão da farsa humana a que sou obrigado a viver e testemunhar. Minha vontade era de sair, desaparecer, perder-me até de mim, não ter a consciência da banalidade e da falsidade das relações. Hoje, já se passaram três anos, e eu vejo, cada vez mais com nitidez e desprezo as pessoas e a sociedade. Não tenho mais crédito em nada, vivo por viver, indiferente. É a minha forma de dizer o meu desprezo, e, ao mesmo tempo, um despreparo absoluto de fazê-lo [...] (Entrevista n. 44). ${ }^{6}$

Eu vivo sozinha, trancada, não ouso falar, e, se pudesse, nem ousava pensar, mas os pensamentos po-

${ }^{6}$ Informante com 29 anos, solteiro, natural e residente na cidade de São Paulo, vendedor autônomo, que perdeu o pai, de 65 anos, vítima de uma longa doença degenerativa. voam como nada a minha cabeça, e, às vezes, eu me sinto louca e enlouquecida de solidão, de não ter com quem desabafar![...] Mas finjo bem. Sei parecer falsa como todos esses que circulam ao meu redor! Quando eles me visitam, eu pareço a pessoa mais leve e feliz do mundo; nunca fui e, agora, cada vez mais, não sou de demonstrar meus sentimentos. Mas a minha vontade era de gritar, chorar, passar na cara de todos a minha solidão e a brutalidade do mundo que parece a todos constranger e que todos parecem negar. Busco fugir de mim, mas me refugio cada vez mais nesta casca oca que me restou e que tento esconder e negar para todos e até [...] Ah, se eu pudesse, para mim mesma [...] (Entrevista n. 37). ${ }^{7}$

Na definição de perda como "ausência", os $32,75 \%$ que assim a apreenderam parecem ter presente, na sua constituição, a ideia de uma distância temporal e espacial de algo ou alguém que funcionasse como o ponto modal de uma rede de significados necessários ao processo integrativo do sujeito consigo mesmo e com os outros. A noção de perda, através da expressão "ausência", parece estar ligada ao processo referencial onde se estabelece o sentido da memória. Os indivíduos, na sua ausência, estão ameaçados de privação de uma faculdade que parecia segura e inerente a si mesmos, que Benjamin (1985, p. 198) chamará de "a faculdade de intercambiar experiências".

Desse modo, tem a ausência, aqui, o sentido de um sentimento de vazio ocasionado por uma relação para a qual o sujeito não se encontra preparado, e de que sente falta. Mas, simultaneamente, não ousa declarar o que sente, por receio de não ser entendido.

A ausência do ponto modal que a perda provoca aliena ainda mais a experiência como troca e solidariedade, como construção. A experiência, pelo contrário, parece caminhar para uma dissolução e, consequentemente, ter seu valor decaindo até seu desaparecimento total.

Isso parece ameaçar os indivíduos com a impossibilidade de comunicação. A possibilidade do inominável ressoa como uma ameaça

${ }^{7}$ Informante de 52 anos, aposentada, viúva recente, sem filhos, natural e residente na cidade do Rio de Janeiro. 
eloquente, onde, aparentemente, apenas resta o anseio nostálgico de um retorno para algo que se perdeu, agora atemporal, para alguma coisa cada vez mais difícil de expressão, a não ser a de um grito mudo, abafado que, se chega a ser ouvido por outros, é escutado como e através de fragmentos incompreensíveis que ampliam a solidão e ameaçam os indivíduos de destruição e isolamento.

É o que parecem revelar os seguintes fragmentos de narrativa:

Tenho dentro de mim uma espécie de nó, que me dói, às vezes até sinto falta de ar. Tudo começou quando eu perdi a minha filha mais velha. Parece que o meu mundo caiu, foi à lona, como diz meu filho... Tento disfarçar, mas acho que não consigo [...] Tento falar e não posso, algo me agarra por dentro e me deixa sem palavras e gestos [...] Por mim, ficava o dia todo sozinha com os meus pensamentos. Penso no tempo em que minha filha ficava perto de mim, de como conversávamos, de como ela era bonita e independente, de como é impossível a vida sem ela [...] Queria dizer isso para os meus, mas não consigo; tentei falar, mas eles entenderam como se eu estivesse doente e queriam me levar à força a um médico [...] Então desisti! Fico só com a minha filha e o meu sofrimento, e levo a vida como posso. Aprendi a ser hipócrita, acho, fingida, o que só aumenta ainda mais o meu sofrimento e a minha solidão [...] Me ponho formal, distante, mas cumpridora das minhas obrigações... Ninguém parece se importar comigo, se eu estou aparentando firmeza, mas estou solitária e frágil, só as lembranças me botam em pé [...] E choro, choro, trancada [...] Mas ninguém nota ou quer notar o meu sofrimento [...] (Entrevista n. 102). ${ }^{8}$

Só vivo das lembranças dele. O mundo já não me importa. Fico em casa, quem quiser que venha me procurar. Recebo bem, mas indiferente. Todos pensam que virei uma bruxa, mas é só dor, só sofrimento o que me move [...] É só a ausência dele em mim. Vivo das recordações do tempo em que era feliz [...] Me basta, pois a dor é a minha sina [...] (Entrevista n. 70$)^{9}$

A terceira categoria que expressa a visão dos informantes sobre a noção de perda

${ }^{8}$ Informante de 63 anos, casada, três filhos, uma mulher e dois homens, aposentada, natural da cidade de Limoeiro, interior de Pernambuco, e desde os vinte anos moradora da cidade do Recife. Perdeu a filha única vítima de um enfarte "fulminante", nas suas palavras.

${ }^{9}$ Informante de 48 anos, viúva, um filho, doméstica, natural de Macapá. Perdeu o marido que, segundo ela: "era tudo para mim, a minha vida, o meu sonho [...]". é construída, por sua vez, através da ideia de "desaparecimento". Essa categoria corresponde a $21,01 \%$ do total de respostas.

A ideia de "desaparecimento", aqui, mais do que a ideia de "ausência", parece alcançar o significado de uma construção melancólica sobre o processo de perda. Nessa construção, os sentimentos para com o social e para consigo mesmo aparentam tender para um tipo de diluição de sentidos. A perda pessoal do sujeito é visualizada através de um processo de ambivalência resultante da vergonha como individuação, e da reprovação ou estranhamento público, como uma consequência, enfim, de sua subjetivação e da falta de expressão no social. O que parece constituir-se, assim, como tendência, em uma crença ilusória de expectativas e no estabelecimento de um grave conflito de sentimentos ambivalentes. É resultante da falta de esperança e do sentimento de que algo esteja prestes a acontecer e eminente a desabar sobre si, do qual, no dizer de Abraham (1976, p. 100), só se pode fugir, voltando para si próprio a hostilidade e a amorosidade que originalmente sentia em relação a seu objeto.

O depoimento de um senhor de 70 anos $^{10}$ sobre o sentimento de desilusão provocado pela morte de sua esposa exemplifica bem essa ideia de desaparecimento, como perda. Para ele:

\footnotetext{
O mundo deixou de existir quando ela morreu [...] Me culpo a todo o momento porque ela e não eu que se foi. O seu desaparecimento provocou em mim um vendaval de questionamentos que não sei responder, a não ser me culpando de não ter dado a atenção merecida quando de sua presença, de não ter ficado o tempo todo com ela quando de sua doença, de não a ter visto na hora de sua morte, na urgência do hospital [...] Por não ter morrido com ela [...] Me culpo, me culpo o tempo todo, mas sou um covarde e não consigo findar minha vida. Se eu tivesse a certeza de que iria me encontrar com ela, poderia, quem sabe, ganhar coragem e ir à sua procura, ficar ao seu lado [...] Mas não, não posso afirmar e tenho quase certeza de que, na morte, se encerra tudo [...]

${ }^{10}$ Informante natural e residente na cidade de Maceió. Engenheiro aposentado, pai de dois filhos homens que administram suas propriedades, e quatro netos.
} 
Então me tranco, me fecho, não quero nada, nem ninguém [...] Meus filhos chegam e eu vou para o meu quarto [...] Não quero que ninguém me veja, tenho receio de ser objeto de estranheza e de falsos interesses sobre mim [...] (Entrevista n. 53).

Intercessão entre o desespero e o tédio, a dor da perda subjetivada e sem expressão no social parece reproduzir-se, assim, na narrativa acima, como ausência de projeto. O processo de perda como desaparecimento tende a tornar-se melancolia.

O processo de individuação do sujeito que sofre a perda - através da ocultação da face e da busca de demonstração de leve indiferença às formas culturais de representação do sofrimento e da morte tradicionalmente usadas - revela, de um lado, uma tendência social, no Brasil atual, de escamoteamento da expressão pública dos sentimentos (Mauss, 1980). Denota, também, a valorização da interiorização como subjetividade ou espaço da intimidade, ou do privado, e, dessa maneira, ela é sentida pelo sujeito como não social, por definição. Além disso, ela cria uma disposição prévia e permanente no indivíduo para a desconfiança no outro, e, por extensão, no social (Koury, 1999; 2003; 2011).

A quarta categoria construída para caracterizar o significado de perda por 7,82\% dos informantes é a de "dano". O termo "dano" é empregado, segundo o Dicionário Aurélio, no sentido de um prejuízo moral. É entendido também como um mal ou ofensa pessoal causado a alguém através da deterioração, da danificação ou da inutilização efetiva, eventual ou iminente de algo pertencente a esse sujeito, seja ele individual ou coletivo.

A perda como "dano", desse modo, é sentida como uma ofensa moral e um sentimento de inutilidade ou deterioração real ou virtual, como se o indivíduo que revelasse tal conceito visse ou vivesse cada dia o seu presente como incerteza, id est, recheado de receios e medos de que algo ou alguém lhe seja tomado, ou está virtualmente próximo de ser dele retirado, sem ter claro o que ou quem foi retirado, ou o que ou quem o retirou. Sente-se logrado, inseguro dos seus gestos, de não saber como se comportar ou o que esperar da avaliação dos outros em relação à sua atitude, ou que atitude tomar a respeito das performances possíveis dos outros.

O sentimento de logro moral que o dano, como definição de perda, parece provocar diz respeito, assim, a uma espécie de desequilíbrio das relações entre o indivíduo e a sociedade. Os ritos de passagem, que conformam um ser moral, aparentemente, deixam de ser sentidos como efetivos, e o questionamento sobre eles cria um hiato entre as marcações das sequências cerimoniais que assinalam os movimentos de um estado socialmente expresso a outro. Informa uma entrevistada ${ }^{11}$ residente na cidade de Recife.

Ele não poderia ter feito isso comigo: ir embora assim, sem mais nem menos, me deixando louca, com filhos para criar, sem ter uma profissão definida e só ter vivido a vida como se só a dele importasse [...] Mas se foi, e pronto! [...]

\section{E continua:}

E aqui estou eu, passados quase sete anos, tendo que me virar, tendo que fazer de tudo para suportar a humilhação de me apresentar sem ele, sem a figura forte e de apoio que era ele para mim [...] Só não morro pelos filhos, mas estou como morta por dentro. Me sinto roubada da minha vida, me sinto constrangida de enfrentar o mundo pelos meus filhos, quando o que queria é ficar na minha, trancada nos meus pensamentos, em minha vontade de dizer a ele que ele acabou com a minha vida quando ele se foi [...] Se eu pudesse adivinhar, não teria aceito dar a minha vida assim não [...] Mas agora é tarde, e só me resta ter que aguentar o desprezo do mundo e o meu desprezo por ele também. Dói moço [...] É uma dificuldade todo dia que amanhece e eu ter que enfrentar tudo outra vez [...] (Entrevista n. 109).

Pelo trecho transcrito acima, é o despreparo para o mundo que parece ocasionar a revolta pela perda do ente querido, e do próprio

11 Informante de 42 anos, mãe de dois filhos menores, funcionária pública. Marido morreu vítima de distúrbios cardíacos. 
ser, que se foi também. Trata-se da revolta por ter sido desamparada, tendo de sobreviver em um mundo para o qual não se considera adaptada e o percebe como cruel. Isso parece causar um mal estar crescente, por não saber ela como se comportar frente a cada movimento de uma marcação social, vista como passagem relacional de tempos e espaços regulados e reguladores das transmutações de uma sociabilidade determinada.

Descrentes do papel das marcações, em um movimento de rejeição por sentirem-nas como inadequadas, mas ao mesmo tempo sofrendo pela perda do valor social de cada passagem, os indivíduos que afirmaram a perda como "Dano" parecem se sentir como logrados, vítimas de um estorvo moral acontecido ou prestes a acontecer, o que os deixa em estado de latência, paralisados e sem ação sobre que conduta tomar a cada movimento cotidiano que lhes impõe participação.

A perda, considerada como "ausência", "desaparecimento", "perda de si” ou "dano", dessa forma, como foi visto até agora, constitui um conjunto compreensivo de categorias através das quais se pode inferir o sentimento do brasileiro urbano de classe média, atual. É claro que essas quatro categorias, para efeito de análise, têm de ser vistas como interrelacionadas, uma influenciando e sendo influenciada pelas demais, por fazerem parte de um mesmo ¿ universo societário e relacional.

înica diferencial que, analiticamentr $\vec{\emptyset}$ na possível sua diferenciação. Gradações enơ tre receios e significados morais na vivência i.

$\therefore$ nos quais uma busca compreensiva tem de se

ลे apoiar para verificação e alcance de sua sim$>$ bologia.

Tais categorias abrem espaços para verificação de como o conjunto de regras e etiquetas e a habilidade social e a perceptividade são sentidas como expressão de diferenças de formas de transmissão e avaliações do outro e de si mesmo, isto é, como manutenção, prevenção ou neutralização de inconsistências do jogo relacional. Elas possibilitam, também, o entendimento sobre as formas pelas quais se estabelecem, entre o indivíduo e os outros relacionais, elementos de insegurança e descrédito pessoal e societário, na vivência de um sentimento de perda, criando um campo de vulnerabilidade entre as partes em interação, fechando-as, ao mesmo tempo, dentro de cada sujeito, no interior de cada gesto e representação, através de uma atitude blasé simmeliana, de indiferença social. Os sentimentos introjetados configuram-se como uma expressão subjetiva e não social. Impõem-se, enfim, como uma máscara para o outro, ou como uma ocultação da face, no dizer de Goffman (1967), para a proteção pessoal em uma situação de risco, na vivência compulsória de um social que não satisfaz.

Parece que se cria um vazio entre segredos que são, ao mesmo tempo, negados e permeados da ânsia de serem descobertos e conquistados. Cada segredo - ou melhor, os complexos de segredos, ou, melhor ainda, os portadores de segredos, isto é, os indivíduos comporta a nuance de uma individualidade e os vazios dos espaços de relações sociais a que se submete e nos quais se conflitua.

A individualidade, assim, se põe contrária ao social e, ao mesmo tempo, nele busca situar-se como indiferença para melhor poder usufruir das relações de opacidade em que se transformaram, ou parecem ter-se transformado, as relações sociais para os sujeitos em relação. A individualidade, porém, ao mesmo tempo, anseia ser tocada, experienciada, vislumbrada, descoberta, encantada e, como tal, se põe à espera.

As quatro categorias com que os informantes pensam a noção de perda parecem se constituir, em nuanças, nessa ambiguidade. São todas regidas por graus de receio e medo de exposição dos indivíduos, mas também do seu contrário: medo de não serem descobertos. 


\section{PERDA E SOFRIMENTO}

Estabelece-se, então, algo, como uma espécie, pelo menos em aparência, de um movimento ritual, novo e ainda inseguro nos seus passos. Marcado pela discrição de gestos e economia de afetos, esse movimento que se gesta parece não habitar no respeito ao outro e a seu segredo, mas, e principalmente, como informa Simmel (1950, p. 321), no respeito a tudo o que o outro não nos revela em expressão, e que deve ser mantido, a todo custo, à distância do conhecimento de cada indivíduo em relação, mesmo que isso possa provocar uma reação em cadeia, e o próprio segredo contido em um ser venha a correr o risco de não ser jamais revelado. Ansiado e, ao mesmo tempo, preservado, o segredo reside nessa ambiguidade insatisfeita do medo de contaminação.

O perigo de não ser entendido constrange, ao mesmo tempo em que o conjunto de mal entendidos a que se expõe ou poderá se expor um sujeito em relação o inibe e o isola. E, nesse movimento ambivalente, parece haver uma espécie de anseio, sem um conhecimento claro sobre o porquê, a um retorno mágico a um tempo e a um espaço perdido, em algum lugar do passado, cuja memória se nega a enquadrar. Tempo e espaço onde seria possível estabelecer um encontro sem correr o risco da perda de si mesmo, ou do desaparecimento do outro da relação. O que poderia até causar danos morais pela ausência sentida, ansiada, mas, ao mesmo tempo, pelo seu lado mágico e distante, evitada, por ser diagnosticada como agente de poluição e causadora de sofrimentos.

A relação entre perda, como sentimento moral, e sofrimento parece ser evidente entre os 1304 informantes do questionário geral desta pesquisa. Mas, como eles compuseram a relação entre esses dois termos? É possível uma comparação entre eles, ou apenas o sofrimento engloba o sentimento de perda como uma espécie de inevitabilidade irremediável?

Perguntados sobre a existência de uma relação entre perda e sofrimento, $77,30 \%$ res- ponderam positivamente, contra $22,70 \%$ de respostas negativas. O interessante a observar é que aqueles que afirmaram não haver relação $(22,70 \%)$ assim o fizeram por acreditar que não existe diferença entre os dois termos. Para os informantes, a perda e o sofrimento são a única face de uma moeda - não uma e outra, mas a mesma face. A perda é sofrimento e o sofrimento é, inevitavelmente, produto de uma perda, seja lá que origem um e outro tenham. Para eles, assim, é impossível pensar uma relação, que implica, em seus cálculos, uma forma de interação entre dois. Pois uma é a outra e vice-versa. Pensar a perda remete sempre ao sofrer, e pensar o sofrimento implica uma referência à perda. Trata-se de um umbilical processo, que parece remeter inevitavelmente para a mesma sensação de impotência, de preenchimento pelo outro e resguardo de si.

Entretanto, os $77,30 \%$ que responderam haver uma relação entre sofrimento e perda, por seu turno, estabeleceram três níveis diferentes para expressar essa relação: o primeiro se refere à diferença de intensidade entre perda de pessoas e de objetos; o segundo indica que perda provoca o sofrimento; e o terceiro, por fim, se expressa como um sentimento de perda eterna.

Assim, 21,53\% dos informantes caracterizaram essa relação através de uma diferença de intensidade entre perda de pessoas e de objetos. A perda objetivada de objetos ou pessoas parece, assim, provocar sofrimento em um indivíduo. Esse sofrimento é uma espécie de consequência graduada e motivada pelo sentimento de posse, ou seja, de não mais possuir os elementos objetais perdidos pelo desaparecimento ou pela desapropriação.

A gradação na intensidade de sentimentos envolvidos em uma perda específica, assim, se vincula ao conteúdo de posse ou de aproximação entre o sujeito que perdeu algo e o objeto ou pessoa perdida. É uma relação objetiva, ocasionada pela ausência e pela impossibilidade, momentânea ou definitiva, de possuir algo ou alguém significativo. Assim, a perda parece 
estar mais próxima das relações de mercado, onde o valor do objeto é medido através da intensidade de ansiedade gerada no sujeito que o possui ou que o perdeu. O sofrimento pode ser medido e quantificado, e diferenciado em intensidade nas gradações entre pessoas e objetos, entre proximidade e apropriação.

A segunda relação estabelecida entre sofrimento e perda é expressa por $47,82 \%$ dos informantes através da afirmativa: a perda provoca o sofrimento. Para esses informantes, o sofrimento é uma consequência da perda, um movimento que parece ser provocado pela ruptura ocasionada pela ausência ou desaparecimento, definitivo ou parcial, porém concreto, do objeto ou da pessoa amada. Reflete o estado de fragilidade em que a pessoa que sofreu uma perda se encontra no momento de tomada de consciência do que perdeu.

O sofrimento seria, desse modo, um tipo de dor moral e física, pela somatização de uma perda objetiva no indivíduo e, ao mesmo tempo, um sentimento de impotência ante a pessoa perdida ou um objeto, e a conscientização dessa perda.

A terceira alternativa para a relação entre sofrimento e perda é expressa por $30,65 \%$ dos informantes. Essa terceira relação, porém, é estabelecida de um modo mais difuso, atra* vés da afirmação de que o sofrimento é um 今 sentimento de perda eterna.

Esse modo de referenciar a relação entre sofrimento e perda não parece circunscrever a relação a uma perda definida e objetiva, como parece expressar a primeira e a segunda forma de relações propostas pelos informantes. Expressa, ao contrário, a relação com um sentimento estilhac çado, pulverizado, disperso no interior do sujeito.

ลิ Parece referir-se a algo ou a alguém não de todo objetivado, como uma espécie de condenação ou desilusão de mundo a que todos e qualquer um estão destinados a percorrer.

A perda passa a ser alguma coisa presente, irremediavelmente enraizada no interior dos sujeitos, que parece ultrapassá-los pela plenitude e eternidade de sua constância. E o sofrimento é a forma de expressão desse sentimento disperso que agride e que acompanha os indivíduos em sua jornada, como uma sina da qual não se tem forma de escapar.

De um lado, a perda faz parte de uma tradição judaico-cristã, situada na perda da inocência e do paraíso, cuja recuperação se realiza através da abdicação de uma vida terrena em prol de uma vida espiritual, plenamente completa na pós-vida, após a morte. Mas, por outro lado, parece realizar-se muito mais pela desilusão do mundo, por não mais sequer situar o objeto perdido, o paraíso ou a inocência, em um lugar mítico ou real do passado, por não ter mais lugar onde originar a perda e o sofrimento dela consequente.

Assim, o sujeito é destinado a vagar como um ser sofredor de uma perda acontecida em algum momento ou em algum lugar indefinido, da qual ele quer se lembrar, se reapropriar, mas cada tentativa o coloca mais distante, e os sentimentos se tornam mais pulverizados, ganhando maior intensidade o seu sofrer.

As três possibilidades de interpretação da existência de uma relação entre sofrimento e perda transmitidos pelos informantes, assim, situam essa relação entre um produto de uma perda objetivada, concreta - onde o sofrimento aparece como uma consequência quase natural da tomada de consciência de um ator de algo ou alguém que se foi, ou de quem se ficou privado - e um produto de uma perda difusa, inatingível em sua origem, que parece gerar uma espécie de nostalgia de algo ou alguém de alguma forma extraviado de sua presença e cuja sensação é de um aniquilamento e irremediável condenação a um sofrimento a ela inerente.

Ricoeur (1994, p. 60-61), em seu estudo sobre o sofrimento, estabelece diferentes degraus da manifestação de uma crise de separação. O primeiro é visto como se o sofredor fosse único e insubstituível. O segundo degrau aponta para o sofredor como um solitário, cujo sofrimento é incomunicável e inapreensível pelos outros, os quais não podem compreender ou ajudar. No terceiro degrau, o outro se apre- 
senta, ou parece apresentar-se como o inimigo do indivíduo que sofre. No quarto e último degrau, enfim, como condicionado e condicionante dos demais, o sofrimento aparece para o indivíduo que o sofre como uma espécie de predestinação, como de ter sido escolhido para sofrer. Esses degraus ricoeurianos parecem assentar-se bem nas expressões utilizadas pelos informantes desta pesquisa.

O sofrimento que informam parece ultrapassar a própria vida do sujeito, exteriorizando-se em eternidade, prendendo-se em uma atemporalidade sem passado e sem futuro, formada pela presentificação contínua e repetitiva do não olvidar, mas, também, não saber ao certo o que e o como esqueceu. O "porquê eu?" é a pergunta e o reflexo do inferno do suportar a dor (Ricoeur, 1994, p. 61). Ser um ser que sofre, predestinado ao sofrimento torna-se um estado que parece tomar conta do sujeito que, sem resposta, parece cair ou em uma forma de conformismo fantasmático ao sofrimento a ele destinado, ou a um ceticismo nas formas de olhar os outros sociais em relação.

Tanto o conformismo fantasmático quanto o ceticismo parecem ser, assim, as formas de enfrentar o mundo, nessa relação entre a perda, o sentimento difuso de perda e o sofrimento a ela inerente. $\mathrm{O}$ mundo apresenta-se, assim, sem confiabilidade, a não ser a da confiança em não ter confiança legítima nas instituições e coisas públicas da ordem social.

Regras e etiquetas de uma sociabilidade são, dessa forma, vistas com uma espécie de desdém e descrédito. A perda é sentida, de um lado, como algo a ser reparado pelo ator, que se culpa pela sua efetivação e, ao mesmo tempo, cria uma escala de gradações por onde possa expiar a sua dor. E, como tal, a dor é sempre pessoal, como sofrimento reparador de culpa, o que individualiza o sujeito e o constrange, ou parece assim fazer, ante o mundo e os outros sociais.

De outro lado, porém, a perda é vista pelo seu lado atemporal. É sentida como uma espécie de condenação impossível de ser reparada, e cujo enfrentamento é o de retomá-la como espaço de criação de uma temporalidade artificial que permita ao sujeito remeter-se a um cotidiano contínuo e repetitivo de "mesmidade”. Não, desse modo, para a existência de uma finalidade; não, também, para uma possibilidade de salvação; e não à existência de outra coisa a não ser de si mesmo.

Nesta eterna repetição, o indivíduo parece recriar-se em cada momento de seu sofrimento, como um ser sempre já perdido e impossível de realizar a ânsia por um fim, como reparação, o que parece provocar um sentimento de vergonha de si mesmo e dos outros em relação a tal sofrimento. Aprisionando, o indivíduo fica envergonhado na busca de um autocontrole que evite do olhar a instabilidade e a tensão. Embora, e ao mesmo tempo, sinta uma ânsia, na intimidade do seu segredo, cada vez mais escondido a sete chaves, ou a necessidade do conforto e do repouso.

Os sentimentos de culpa e de vergonha parecem satisfazer, assim, os parâmetros por onde se compreende a relação por eles estabelecida entre sofrimento e perda. Os sentimentos de vergonha e culpa, ao serem tomados como dois sentimentos diferenciais (Lynd, 1961) - o segundo como um sentimento mais individualista, e o primeiro como que ainda encoberto por uma malha por onde se espelha a tecedura de uma coletividade - podem ser usados para pensar a sociabilidade urbana brasileira, principalmente entre os segmentos médios urbanos, que vivem uma transformação na esfera do comportamento e da mentalidade dos seus atores.

A principal característica dessa mudança comportamental reside em, ou tem por seu núcleo ou centralidade, um desapego crescente ao passado e às suas tradições, de um lado; e, de outro, um se lançar a um novo modelo cujos hábitos, não de todo claros e não de todo incorporados, apresentam-se como constrangimento pessoal.

Apresentam-se como uma espécie de não saber agir, ou de não ver como colocar-se em situações de passagens, onde os elementos de 
ruptura ou de transição ficam mais acentuados, provocando mal estar, incerteza, e uma dose maior de disfarce e máscara, de indiferença, para melhor esconder a face, e, com ela, ausentar-se ou negar o enfrentamento direto com as situações de risco que o cotidiano lhe impõe.

O conformismo fantasmático, o ceticismo social das coisas públicas e a descrença pessoal nas instituições asseguradoras da cultura e do social como tradição parecem, desse modo, se ampliar. Tudo isso faz os indivíduos tornarem-se, ao mesmo tempo, eternos seres à procura de algo ou de alguém, a que ou a quem se possa amparar, mesmo sob a capa céptica com que aparecem vestidos. É o movimento de um processo ambíguo, que provoca mais pessimismo, mesmo que transfigurado em uma alegria carnavalesca, ou em um tudo qualquer que vira piada na mesa de um bar.

\section{CONCLUSÕES}

Este artigo teve como principal objetivo a compreensão das mudanças comportamentais da população brasileira urbana frente ao fenômeno do luto e da perda. É resultado de um grande mapeamento do comportamento do homem brasileiro, de segmentos médios urbanos, e das mudanças experimentadas na sua ণิ sensibilidade, no decorrer da segunda metade Фं da última década do século XX, tendo o proCesso de luto e da perda como "mote" analítico. i Em primeiro plano, trata da ambivalência vivida por esses indivíduos nas formas de sociabilidade, emergidas com uma impetui osidade e rapidez impressionantes no Brasil \& urbano dos anos de 1970 até os dias de hoje, సે em que se observa uma disposição para uma forma mais contida de expressão social dos sentimentos e, ao mesmo tempo, o caminhar para uma esfera crescente da intimidade, com 牙 o aumento da solidão individual e um refreamento das formas de solidariedade.

Uma espécie de vergonha de expressão dos sentimentos parece emergir, como se isso pudesse contagiar o outro e desvendar a si mesmo, tornando o eu e os outros frágeis, fechados cada um no seu íntimo, individual, e fora dele, ou melhor, excluídos do social. Concomitantemente, porém, também como movimento de intimidade, vê-se um desejo de se ser descoberto e acalentado pelo outro, o que aumenta a ambiguidade das ações entre os homens. A sociedade brasileira parece, assim, caminhar para uma esfera de relações cada vez mais mercantilizadas e formais, e o individualismo tende a se estabelecer como a nova forma da sensibilidade do homem urbano, de classe média, no Brasil do século XXI, mesmo com regras de etiqueta comportamentais frágeis e ambíguas, o que aumenta o sofrimento social do não saber como agir entre os que sofrem a perda e os que têm de lidar com ela em relação aos relacionais em luto.

Recebido para publicação em 30 de outubro de 2012 Aceito em 06 de novembro de 2013

\section{REFERÊNCIAS}

ABRAHAM, Karl. Teoria psicanalítica da libido. Rio de Janeiro: Imago, 1976.

BENJAMIN, Walter. O narrador:considerações sobre a obra de Nikolai Leskov. In: __ Obras Escolhidas: magia e técnica, arte e política. São Paullo: Brasiliense. 1985. v. 1.

DaMATTA, Roberto. A questão da posse: tempo, sociedade ritual e estado no Brasil. Humanidades, São Paulo, v.1, n. 2, p. 36-45, jan./mar. 1983.

A casa \& a rua: cidadania, mulher e morte no Brasil. Rio de Janeiro: Guanabara. 1987.

ELIAS, Norbert. O processo civilizador: uma história dos costumes. Rio de Janeiro: Jorge Zahar. 1990. v. 1.

GOFFMAN, Erving. On face-work: an analysis of ritual elements in social interaction. In: Interaction Ritual. Essays on face-to-face behavior. New York: Anchor Books, 1967. p. 05- 45,

JUNQUEIRA, Carmen. Ritos de passagem de nossa infância. São Paulo: Summus, 1985.

KOURY, Mauro Guilherme Pinheiro. A dor como objeto de pesquisa social. Ilha. Revista de Antropologia, Florianópolis, v. 1, n. 0, p. 71-83,out.1999.

Sociologia da emoção: o Brasil urbano sob a ótica do luto. Petrópolis: Vozes. 2003.

Luto e sociedade no Brasil do final do século XX: o imaginário sobre a morte, a dor e a perda na cidade de João Pessoa, Paraíba, Brasil. Revista Latinoamericana de Estudios sobre Cuerpos, Emociones y Sociedad, Córdoba, v. 3, n. 5, p. 6-14, abr./Jul. 2011. 
LYND, Helen. On shame and the search for identity. New York: Science Editions. 1961

MAUSS, Marcel. A expressão obrigatória no indivíduo dos sentimentos. In: FIGUEIRA, Sérvulo Augusto., (Org.) Psicanálise e ciências sociais. Rio de Janeiro: Francisco Alves, 1980. p. 56-63.

RICOEUR, Paul. La Souffrance n'est pas la Douleur. In: Souffrances: corps et âme, épreuves partagees. Paris: Souffrances: corps

SIMMEL, Georg. Discretion. In: WOLFF, Kurt H. (Org).

The sociology of Georg Simmel. New York: The Free Press,

1950. p. 320-324.
A metrópole e a vida mental. In: Velho, Otávio Guilherme (Org.), O fenômeno urbano. Rio de Janeiro: Zahar Editores, 1967. p. 13-28.

VAN GENNEP, Arnold. Os ritos de passagem: um estudo sistemático. Petrópolis: Vozes, 1978.

VELHO, Gilberto. Subjetividade e sociedade: uma experiência de geração. Rio de Janeiro: Zahar. 1986

WEBER, Max. Economía y sociedad. 4 vols. Buenos Aires: Paidós. 1944. 


\section{MOURNING IN BRAZIL AT THE END OF THE 20 $^{\mathrm{TH}}$ CENTURY}

\section{Mauro Guilherme Pinheiro Koury}

This article aims to contribute for the understanding of the behavioral changes in the urban Brazilian population regarding mourning and loss. It is the result of a broad mapping of the behavioral of Brazilians from average urban segments, and of the changes experienced in their sensibility during the second half of the $20^{\text {th }}$ century, using mourning and loss as a guide for analysis.

KEYWORDS: mourning, loss, bereavement, shame, individualism, urban Brazil.

\section{LE DEUIL AU BRÉSIL À LA FIN DU XXe SIÈCLE}

\author{
Mauro Guilherme Pinheiro Koury
}

L'objectif de cet article est d'apporter une contribution à la compréhension des changements de comportement de la population brésilienne urbaine face au phénomène de deuil et de perte. Il résulte d'un quadrillage du comportement de l'homme brésilien, de segments de la classe moyenne urbaine, et des changements qui ont eu lieu au niveau de sa sensibilité au cours de la deuxième moitié de la dernière décennie du XXe siècle, le processus de deuil et de perte en constituant un attribut analytique.

Mots-Clés: Travail de deuil. Sentiment de perte. Souffrance. Honte. individualisme, Brésil urbain.

Mauro Guilherme Pinheiro Koury - Doutor em Sociologia. Professor do Programa de Pós-Graduação em Antropologia da Universidade Federal da Paraíba. Coordenador do Grupo de Pesquisa em Antropologia e Sociologia das Emoções (GREM). Trabalha com temas relacionados à área de Antropologia e Sociologia, com ênfase nas linhas de pesquisas em Sociologia e Antropologia das Emoções; em Sociologia e Antropologia Urbana; e em Sociologia e Antropologia da Imagem e do Visual. Seus trabalhos de pesquisa atuais ligam-se às temáticas: Fotografia e Sociedade, Medos Urbanos, Sociologia e Antropologia Urbana, Cidade e Cotidiano, Sociologia e Antropologia da Imagem e Sociologia e Antropologia das Emoções. Publicações recentes: Estilos de vida e individualidade . Curitiba: Appris, 2014; Práticas instituintes e experiências autoritárias. Rio de Janeiro: Garamond, 2012; Amor e dor. Recife: Edições Bagaço, 2005; Sociologia da emoção: o Brasil urbano sob a ótica do luto. Petrópolis: Vozes, 2003. 